\title{
ANALYSIS OF THE APPLICATION OF SOCRATIVE AS A TOOL FOR THE LEARNING IMPROVEMENT IN A SUBJECT OF EXPERIMENTATION IN CHEMICAL ENGINEERING
}

\author{
B. García-Fayos, M. Sancho, J.M. Arnal, E. Zuriaga-Agustí, I. López-Hernández \\ Chemical and Nuclear Engineering Department, Universitat Politècnica de València (SPAIN)
}

\begin{abstract}
Experimentation in Chemical Engineering III is a compulsory subject of the third course, semester B of the Chemical Engineering Degree at the Universitat Politècnica de València. It is the last experimental subject of the degree, and it applies the POL methodology ("Project Oriented Learning"). The students carry out experimental sessions, obtaining data that they later use to design an industrial installation based on the laboratory equipment but at a large scale. The course is assessed through the design project and a laboratory report of each experimental session, which is corrected by the teacher and then used as study material for the exam. Although the development of the subject is satisfactory, the teachers do not know the level that the students have about the experiment to be developed at the beginning of the experimental session and, in most of the cases, mistakes or errors of interpretation that they have had during the practice are detected during correction of the report. Therefore, last year lecturers decided to introduce the use of the Socrative tool to conduct surveys to students at the beginning and end of the session, in order to have real-time feedback on the points that should be most emphasized during the practice, as well as the degree of improvement achieved after the session. Socrative allows to carry out surveys in a simple way through the mobile phone, and to know at the same time the results of the assessment. Thus, students know their mistakes in the test before starting the experimental session, which also serves them to assess their level about the topic to develop and pay attention to find out those questions asked in the test in which they have obtained worse results.

This work describes the implementation of this teaching innovation in the laboratory, as well as the results obtained and the degree of improvement achieved by comparing the results at the beginning and end of each experimental session. Finally, it is analyzed the usefulness of the innovation, as well as the necessary improvements to continue its application in the future academic courses.
\end{abstract}

Keywords: experimentation, Chemical engineering, Socrative, surveys, laboratory.

\section{INTRODUCTION}

In the context of today's Higher Education, it is necessary to involve students in their own learning process. To do this, it is necessary to motivate the students and awaken in them an interest in the subject being taught, as well as to show them the usefulness of this subject for the development of their future professional activity. In a technological and global world like the present one, the integration of learning methodologies with information and communication technologies (ICTs) is fundamental to approach the new generations of students. Students use information and communication technologies (ICT) frequently and for different purposes ranging from basic notetaking to searching for information, presenting content, solving T-L activities or communicating [1]. The use of these technologies aims to improve students' learning and performance, and encourage their participation and motivation.

In addition, the use of these systems helps effective formative assessment through the feedback provided to the students [2].

One of the examples of the use of ICTs in the learning environment is the use of tools for conducting surveys or questionnaires in real time. There are different tools, such as Moodle, Pear Deck, Quizizz, Kahoot or Socrative. All of them are similar, with some differences such as the question format they allow (Socrative and Pear Deck allow multiple choice and short answer questions); the time for each question (only Pear Deck and Socrative have control over the time decided by the teacher, the rest set 30 seconds to answer); the order of the questions (if it can be random or not, all of them allow it except Pear Deck); or the complexity of the questions allowed (being the ones that allow more complexity Quizizz or Socrative) [3] . All of them are valued in a similar way by students in terms of ease of use, being Socrative better valued by teachers, because it 
allows better monitoring of student progress, and it encourages active listening and daily interaction of the teacher with the student, since the questions are solved face-to-face at the end of each session [1].

Socrative is a free tool for the creation of questionnaires that can be used with smartphones and tablets or by computer through different interfaces (website, iOS, Android). It has different questionnaire options, ranging from multiple choice questions, short answer questions and True/False questions. During the survey, students can receive feedback on the correct answer, and even a brief explanation, and at the end, the success rate. At the same time, the teacher sees the students' answers and their results in real time. A report is immediately generated with a global vision of the questionnaire for the group, for each student and for each question, as the questionnaires are automatically corrected.

This allows to obtain instant feedback on the level of understanding of the students, allowing the lecturer to reorient the class to reinforce those aspects that require it. There are different experiences of the use of this tool in the university environment, and specifically in scientific-technical careers such as theoretical and practical subjects of Industrial engineering [4], subjects of Civil engineering [5], subjects of chemistry in Odontology or Pharmacy [6], subjects of materials science in Chemical engineering or graphic representation of engineering in Agricultural and Environmental Engineering [7] with excellent results, emphasizing a greater receptivity of the students, increase of participation, great adaptation to the tool, greater linkage to the subject [4-7] and an improvement of transversal skills such as understanding and integration [7].

The use of these tools is very useful in environments such as the laboratory, where students cannot access with computers but with tablets or smartphones. There are some previous experiences using this tool in laboratories as Fluid mechanics laboratories for engineers [8], or experimental subjects in Industrial Chemical Engineering [9] in which a similar conclusion has been reached about the usefulness of the interactive tool Socrative in terms of achieving a measurable improvement in knowledge, increasing student participation and performance, and facilitating a better environment for asking and receiving answers to classroom questions. In addition, the use of the tool prior to the beginning of the practice serves to detect the level of preparation of the session by the students [9].

This paper describes the case of an experimental subject of the Chemical Engineering Degree of the Universitat Politècnica de València, in which Socrative has been used for the first time to measure the initial level of preparation of the students of the experimental session and to detect the items that should be reinforced along the practical session. It has also been used to evaluate the level of improvement in student learning and the quality of academic work done at the end of the experimental session.

\section{METHODOLOGY}

Experimentation in Chemical Engineering III is a compulsory practical subject of 4.5 ECTS credits of the third course, semester B of the Chemical Engineering Degree at the Universitat Politècnica de València. It is the last experimental subject of the degree, and it applies the POL methodology ("Project Oriented Learning"). For the academic year 2019-2020 the subject had 56 students, divided in 4 groups that enter to the lab separately each weekday. The students carry out five experimental sessions of 3 hours and 45 minutes, obtaining data that discuss in a laboratory report that they deliver at the end of the lab session. The experimental sessions and their contents are shown in Table 1.

Table 1. Experimental sessions contents

\begin{tabular}{l|l}
\hline \multicolumn{1}{c|}{ SESSION } & \multicolumn{1}{c}{ DESCRIPTION AND OBJECTIVES } \\
\hline $\begin{array}{l}\text { 1-Safety and health } \\
\text { principles in the lab }\end{array}$ & $\begin{array}{l}\text { Basic concepts about safety and health. Personal protective equipment, action in case of fire, spills } \\
\text { or leaks, first aid. Collective protection measures. Use and interpretation of the safety data sheet of } \\
\text { a flammable chemical product. }\end{array}$ \\
\hline $\begin{array}{l}\text { 2- Grounding and } \\
\text { sieving }\end{array}$ & $\begin{array}{l}\text { Characterization of a granular material. Obtaining its main characteristics. Analysis of the influence } \\
\text { of the variables crushing time and number of balls on the particle size of the crushed material. } \\
\text { Optimization of the process to obtain the largest size. }\end{array}$ \\
\hline $\begin{array}{l}\text { 3- Solid-liquid } \\
\text { extraction }\end{array}$ & $\begin{array}{l}\text { Seed oil extraction with organic solvent. Observation of the operation of the extractor. Monitoring } \\
\text { the evolution of the extraction through the composition of the extract and refining. Determination of } \\
\text { the optimal number of stages. }\end{array}$ \\
\hline
\end{tabular}




\begin{tabular}{l|l}
\hline 4- Distillation & $\begin{array}{l}\text { Distillation of the extract to obtain pure seed oil and reuse of the solvent. Monitoring of the boiling } \\
\text { temperature of the mixture and composition of the distillate over time. }\end{array}$ \\
\hline $\begin{array}{l}\text { 5- Active carbon } \\
\text { adsorption }\end{array}$ & $\begin{array}{l}\text { Valorization of the refining of the S-L extraction by its transformation into active carbon. Monitoring } \\
\text { of the continuous and discontinuous adsorption process. Adsorption isotherm calculation. }\end{array}$ \\
\hline
\end{tabular}

The general aim of all the experimental sessions is the observation of the functioning of the laboratory equipment and the data obtained that are used as a basis for the realization of the design of an industrial installation. The course is assessed through the design project and the laboratory reports, which are corrected by the teacher and then used as study material for the final exam.

The realization of practical subjects like this, requires a preparation of the session by the students that does not always occur. Since the beginning of the subject (academic course 2012-2013), we tried to improve this situation, with the obligation to make a pre-report before entering the laboratory. However, result was not as expected, since the report was only made by one member of the group, or each member maked a part of it, losing the thread of the overall session. This forces the lecturer to make a more detailed explanation of the experiment before the start of the practice to ensure the success of the session. In spite of this, failures and errors are detected in the realization of it or in the interpretation of what happened in the laboratory, when the teachers correct the reports of the practice delivered after it. This feedback is received weeks after the session, which reduces the effectiveness and usefulness for the students and only serves for the student to study with better material for the final exam.

Therefore, in the academic course 2019-2020 lecturers decided to introduce the use of the Socrative tool to conduct surveys to students at the beginning and end of the session, in order to have real-time feedback on the points that should be most emphasized during the practice, as well as to measure the degree of improvement achieved by the students after each session.

In each session, students enter the laboratory and after receiving a brief explanation about the experiments to do, they take a pre-session test. Pre-test has ten questions about the experimental session to be developed. Students are free to register with their real name or figured. Test takes 5-10 minutes (time for doing it is free but the time given is in this range). When they finish, they receive information about their global final score, but not about particular mistakes in each answer. This strategy awakens in them the curiosity and the doubt of knowing in which questions they have succeeded and in which not, either by mistake of concept or by answering at random.

After, doing the Pre-test, the students carry out the experiment and write the laboratory report, where they answer questions similar to those in the initial test. At the end of the experiment, the students deliver the daily report and then take the Post-session test. This post-test contains the same questions as the pre-session test. In this case, the students receive information about the correct answer for each question during the test and, at the end, they receive information about the final score obtained.

When everyone has finished the post-test, lecturer comments the answer to each question, the average percentage of correct answers of the group, and the highest and lowest score obtained by the group. These comments are based on the real-time information provided by the Socrative application that is consulted by the lecturer through its smartphone. A scheme of the methodology is shown in Figure 1.

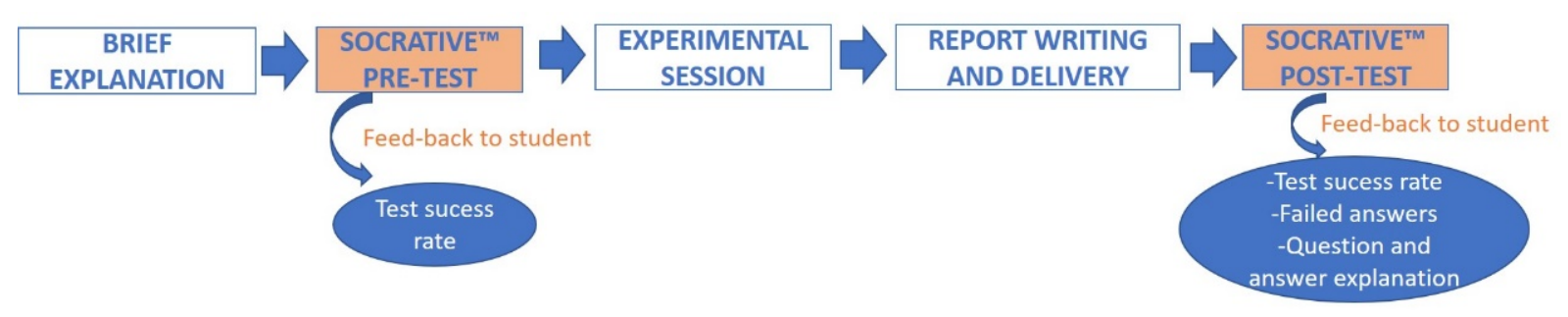

Figure 1. Methodology to integrate Socrative ${ }^{\mathrm{TM}}$ test in experimental sessions of Chemical engineering courses.

Socrative provides an Excel report with the results of each test, indicating the successes and failures for each question for each student, and for the whole group, that will be proccessed and analyzed in the Results Section. For the analysis of the results, the average grade obtained in the pre-test and post-test in each lab session will be analyzed. Grades of the laboratory reports from the academic 
year 2019-2020 and 2018-2019 will also be analyzed in order to determine the improvement over the average mark obtained as a consequence of the Socrative implementation.

\section{RESULTS}

\subsection{Analysis of test results}

Firstly, Figure 2 shows the average results of the percentage of successes obtained in the pre-session and post-session tests carried out in each of the experimental practices.

The average percentage of successes in the pre-session test is $61.4 \%$ on average, being the lowest $49.8 \%$ (Practice 2 "Grinding and sieving") and the highest $77.6 \%$, (Practice 3 "Solid-Liquid extraction"). The average success rate in the post-session test is higher ( $80.2 \%$ on average), being the lowest $73.3 \%$ obtained in Practice 2 "Grinding and sieving" and the highest at $91.1 \%$, corresponding to session 5 of "Active carbon adsorption". The session in which the percentage of improvement is higher is in the practice 4, "Distillation" with a value of $51.4 \%$.

It can be seen that in all the experimental sessions, the percentage of successes in the post-session test is higher than in the pre-session test, which means that carrying out the practice improves the result obtained in the Socrative test. It has been discarded that this improvement is due to the fact that the students take the same test twice and therefore learn the questions and the correct answers, since the students do not know the questions they have failed and are only given information about their global score.

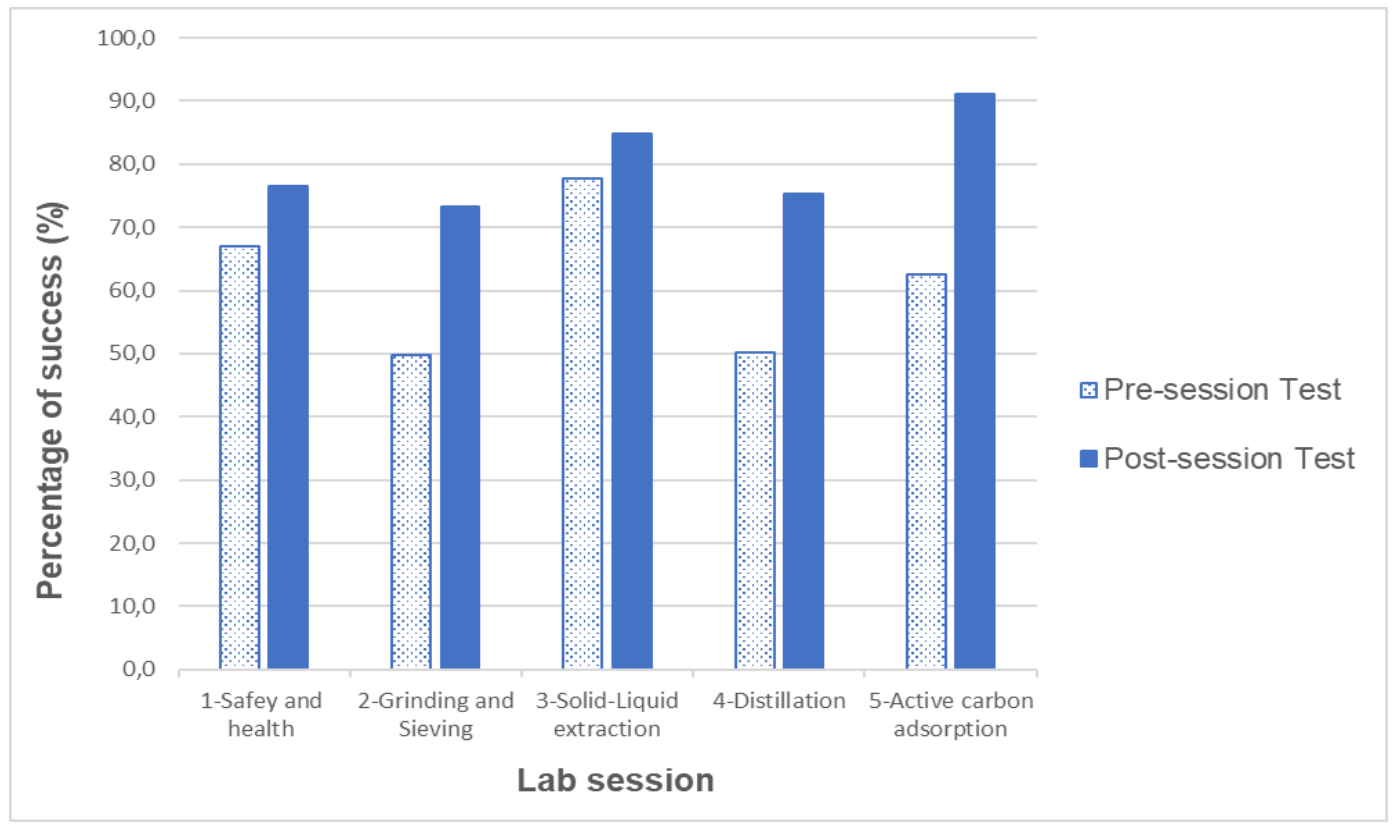

Figure 2. Percentage of success in the pre and post-session test in each lab session.

It is also observed that there is an improvement effect as students practice this type of methodology, since it is observed that the results achieved in the post-session test are greater as the sessions evolve, except for the Distillation practice, which is lower, but it also started from a very low success rate. In fact, in session 1 the success rate in post-session test is $76.5 \%$, reaching $91.1 \%$ in session 5 . This is indicative of a progressive adaptation of the students to the methodology, a greater involvement in the practical sessions to achieve a higher score in the final post-session test. It should be noted that the post-session test grade is not used for the calculation of the course grade.

\subsection{Analysis of the influence of Socrative testing on the quality of laboratory reports}

Usually the experimental session was carried out and after report was elaborated and given to the teacher for evaluation. With the educational innovation raised in the 19-20 course, it was proposed 
that, after carrying out the experiments, the students write the laboratory report and then they made the post-session test.

Results in Table 2 show the score obtained in the laboratory report in each session, in the course 1819 (prior to educational innovation) and in the course 19-20 (when educational innovation has been implemented). It has also been calculated the percentage of improvement in the score obtained in the lab reports.

Table 2. Comparison of laboratory report grades over 10 points.

\begin{tabular}{l|c|c|c|c|c}
\hline \hline \multicolumn{1}{c|}{ Academic year } & Session 1 & Session 2 & Session 3 & Session 4 & Session 5 \\
\hline $18-19$ & 6.0 & 8.2 & 8.6 & 6.8 & 8.7 \\
\hline $19-20$ & 8.6 & 8.5 & 8.5 & 7.7 & 8.5 \\
\hline Grade's percentage of improvement (\%) & 44.4 & 4.1 & -1.2 & 13.5 & -2.0 \\
\hline \hline
\end{tabular}

Table 2 shows that in the academic year 19-20, the report score has improved in 3 of the 5 sessions carried out (specifically in sessions 1,2 and 4). The highest score is 8.6 points out of 10 (obtained in session 1) and the lowest is 7.7 points out of 10 (obtained in session 4). These sessions are the ones in which the lowest scores were obtained in the academic year 18-19 (session 1, 6 points out of 10 and session 4, 6.8 points out of 10), and in which the highest percentage of improvement has been achieved after the implementation of this educational innovation $(44.4 \%$ in session 1 and $13.5 \%$ in session 4). It should be noted that in session 1, a methodological change was made, that might have contributed to the improvement of the results. In the course 18-19 an explanation of theory and realization of the report was made. In the course 19-20, the time of the theoretical explanation was reduced, a visit to the laboratory was introduced, as well as a putting into practice of the theory, with the writing and real application of a work protocol in the laboratory. In sessions 3 and 5 , the qualification has remained practically constant with respect to the academic year 18-19.

\subsection{Relationship between laboratory report score and post-session test report}

Finally, the possible correlation between the score of the laboratory report and the post-session test score is analyzed. As already mentioned, the laboratory report score has improved with respect to the previous course scores and it remains approximately constant throughout all the sessions, and the post-test scores have improved with respect to the pre-test scores.

Table 3 shows the comparison between the post-test session and the laboratory report scores. In this case, it is observed that, in the first sessions (session 1 and 2), the post-session test score is lower than the one of the laboratory report. This result differs from what it was expected because the test is performed after the delivery of the report. This may be due to the fact that the laboratory report is done in a group and the test is done individually, and also because it is a new methodology to which the students were not used to in the laboratory sessions. In session 4, the result is the same. In the third session, the score is similar to the lab report and it is higher in the fifth session. This shows that the students have required a progressive adaptation to this type of methodology throughout the experimental sessions, which results in an enhanced use of the session, and is reflected not only in the level of the laboratory report achieved but especially in the increase of the final test score, with the exception of the distillation session.

The students are able to improve their results because they learn to distinguish which are the key concepts of the practice through the initial test, they understand them when doing the practice, they integrate them when doing the laboratory report and they demonstrate them when doing the final test.

Table 3. Comparison of laboratory report and test grades over 10 points.

\begin{tabular}{l|c|c}
\hline \hline \multicolumn{1}{c|}{ Laboratory session } & Laboratory report & Post-session test grade \\
\hline 1-Safety and health & $8.6 \pm 0.7$ & $7.7 \pm 0.9$ \\
\hline 2-Grinding and Sieving & $8.5 \pm 0.8$ & $7.3 \pm 1.5$ \\
\hline 3-Solid-Liquid extraction & $8.5 \pm 0.8$ & $8.5 \pm 1.8$ \\
\hline 4-Distillation & $7.7 \pm 0.4$ & $7.5 \pm 1.3$ \\
\hline 5-Active carbon adsorption & $8.5 \pm 1.1$ & $9.0 \pm 1.0$ \\
\hline \hline
\end{tabular}




\subsection{Survey design for collecting student opinion about Socrative test methodology}

The results obtained show the importance of the methodology implemented and will be maintained in the next academic years. However, it would be necessary to obtain the qualitative opinion of the students about this new methodology in order to have additional information beyond the improvement of the academic performance.

A survey for being implemented with Socrative tool has been designed for this purpose and it is shown in Table 4. The survey has 10 questions, and a multiple choice answers, based on a Likert scale of 5 levels (Totally agree, Agree, Indifferent, Disagree, Strongly disagree). The survey will be used in the present academic year 2020-2021.

Table 4. Comparison of laboratory report and test grades over 10 points.

\begin{tabular}{c|l}
\hline \hline Number & \multicolumn{1}{c}{ Question } \\
\hline 1 & Using Socrative with my smartphone has been very easy \\
\hline 2 & $\begin{array}{l}\text { I find it more useful to do a test before starting the practice than to } \\
\text { do a daily report to understand what I have to do in practice }\end{array}$ \\
\hline 3 & $\begin{array}{l}\text { Knowing the result of the initial test has helped me to realize my } \\
\text { level in practice before starting }\end{array}$ \\
\hline 4 & $\begin{array}{l}\text { Knowing the result of the initial test has helped me to know what I } \\
\text { had to focus on more }\end{array}$ \\
\hline 5 & Knowing the result of the initial test has made me nervous or sad \\
\hline 6 & I think I'll get a good score on the lab report I've done \\
\hline 7 & I was happy to learn that my final test result had improved \\
\hline 8 & If the test counted in the final grade I would take it more seriously \\
\hline 9 & $\begin{array}{l}\text { The lecturer's explanation at the end of the post-session test has } \\
\text { helped me to clarify those concepts that were still unclear }\end{array}$ \\
\hline 10 & After the practice I still have doubts \\
\hline \hline
\end{tabular}

\section{CONCLUSIONS}

The implementation of the Socrative tool in the course has led to the following conclusions:

- Socrative is a simple tool to use and useful for real time testing in the laboratory.

- The performance of pre-session and post-session test in the experimental sessions serves to increase the involvement and motivation of students in the practice, as well as their better use of the session.

- As a consequence of this educational innovation, the score of the initial tests has improved by $26 \%$ and the score of the laboratory reports has been maintained or increased up to $10 \%$, compared with the previous academic course.

- The students need two weeks to adapt to the new methodology and to show a positive evolution in the scores of their post-session tests. The improvement of the laboratory reports grade has been achieved from the first week of application of the methodology.

- The realization of pre and post-test in the experimental sessions provides instantaneous feedback to the teacher that allows to redirect the session and highlight the concepts in which there are more errors or confusion.

\section{REFERENCES}

[1] S. Cosi, N. Voltas, J.L. Lázaro-Cantabrana, P. Morales, M. Calvo, S. Molina, M. Ángeles Quiroga, "Formative assessment at University using digital technology tools", Profesorado, vol. 24, no. 1, pp.165-183, 2020. 
[2] I. D. Beatty, W. J. Cerace, W. J. Leonard, R.J. Dufresne, "Designing effective questions for classroom response system teaching", American Journal of Physics, vol. 74, no. 31, pp. 31-39, 2006.

[3] The Flipped Classroom, Accessed 9 January, 2021. Retrieved from: https://www.theflippedclassroom.es/comparando-herramientas-para-crear-juegos-quizzes-test/

[4] A. González González, A. Sánchez Ríos, C. Cruz García, D. Rodríguez Salgado, "A proposed methodology to evaluate educational competences in engineering degrees based on electronic devices and open access software", International Journal of Engineering Education, vol. 34, no. 4, pp. 1150-1158, 2018.

[5] N. Balta, K. Tzafilkou. "Using Socrative software for instant formative feedback in physics courses", Education and Information Technologies, vol. 24, no. 1, pp. 307-323, 2018.

[6] M.V. Frias, C. Arce, P. Flores-Morales, "Uso de la plataforma socrative.com para alumnos de química general”, Educación química, vol. 27, pp. 59-66, 2016.

[7] J.D. Badia Valiente, F.O. Cazevieille, J.M. Navarro Jover, "Quizzes to evaluate comprehension and integration skills", Journal of Technology and Science Education vol. 6, no. 2, pp.75-pp.90, 2016.

[8] E. Assureira, M. Assureira, "Methodological innovation applied in Fluid Mechanics laboratories", Proceedings of the LACCEI international Multi-conference for Engineering, Education and Technology, 2019. DOI: 10.18687/LACCEI2019.1.1.264

[9] J. Santos, L. Parody, M. Ceballos, M.C. Alfaro, L.A. Trujillo-Cayado, "Effectiveness of mobile devices as audience response systems in the chemistry laboratory classroom", Computer Applications in Engineering Education, vol. 27, pp. 572-579, 2019. 